\title{
ARTICLE
}

\section{Development of Personal Safety \& Interlock System for the Proton Accelerator Research Center of PEFP}

\author{
Sung-Sik PARK ${ }^{1 *}$, Jun Yeon $\mathrm{KIM}^{1}$, Jang-Hyung $\mathrm{CHO}^{1}$, Kyeong-Jun MUN ${ }^{1}$, Jin Sam CHO ${ }^{1}$, \\ Gye Po JEON ${ }^{1}$, Yi Sub MIN ${ }^{1}$ and Jung min NAM ${ }^{1}$ \\ ${ }^{1}$ Proton Engineering Frontier Project, Korea Atomic Energy Research Institute, \\ Daedeok-Daero 1045, Dukjin-Dong Yuseong-Ku, Daejeon, 305-353, Korea
}

\begin{abstract}
The Proton Engineering Frontier Project (PEFP) planned to construct a high power $100 \mathrm{MeV}$ proton linear accelerator and to supply $20 \mathrm{MeV}$ or $100 \mathrm{MeV}$ proton beams to users who want to utilize a proton beam for their Research \& Development. When using high power $100 \mathrm{MeV}$ Proton linear accelerator, a high radiation field is formed in the surrounding area. So the substances are radiation-activated. For this reason, Personnel Safety \& Interlock System (PSIS) in Proton Accelerator Research Center (PARC) of PEFP, which is now under construction, was designed to protect people from radiation hazards by controlling access to restricted areas and interrupting accelerator operation in case of an accident.
\end{abstract}

\section{KEYWORDS: Accelerator, Personal Safety \& Interlock System, Radiation, philosophy}

\section{Introduction}

PEFP of Korea Atomic Energy Research Institute was established as one of the 21st Century Frontier R\&D Programs by Ministry of Science \&Technology, is aiming to develop the $100 \mathrm{MeV}, 20 \mathrm{~mA}$ proton linear accelerator as a user's facility for scientific and industrial utilization ${ }^{1-3)}$, and planning to complete the construction of PARC at Hwacheon-ri, Geoncheon-eup, Gyeongju-si, Gyeongbuk, Korea, in order to install the developed machines.

Figure 1 shows PARC Site, Buildings \& Supporting Facilities.

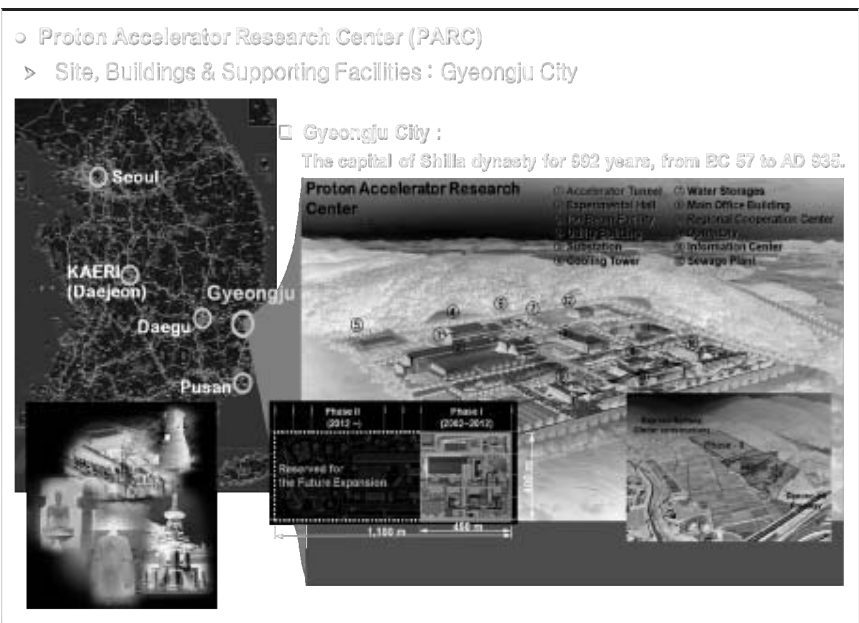

Fig. 1 Bird's-eye view of PARC Site, Buildings \& Supporting Facilities.

*Corresponding Author, E-mail:pssik@kaeri.re.kr

(C) 2012 Atomic Energy Society of Japan, All Rights Reserved.
The proton beam experiment facilities, using high power $100 \mathrm{MeV}$ proton linear accelerator, include five of $20 \mathrm{MeV}$ experiment target rooms and five of $100 \mathrm{MeV}$ experiment target rooms on the basis of user requirements. When using high power $100 \mathrm{MeV}$ proton linear accelerator, a high radiation field is formed in the surrounding area. So the substances are radiation-activated. And according to beam current, target materials, beam irradiation, beam time and operation scenario, each target room has its own operation and access mode. $20 \mathrm{MeV}$ and $100 \mathrm{MeV}$ beam utilities are not allowed to operate simultaneously.

For this reason, special Personnel Safety \& Interlock System (PSIS) is required for protection from radiation hazard, according to a measured radiation levels delivered by Radiation Monitoring System (RMS). The PSIS controls access to the restricted areas of the PARC in order to guarantee the safety and protect the lives of people from radiation hazards, abnormal accelerator operation, and unexpected accidents. In this paper, we describe the design criteria, the logic, and the implementation of PSIS at the PARC of PEFP.

\section{Personnel Safety \& Interlock System Design. \\ 1. Access Control Areas Definition}

Figure 2 shows the layout of radiation area of accelerator $\&$ beam experiment hall building which is the core in PARC. In PARC, access control areas are classified into three types in accordance with the radiation level of each area.

- Red color : high radiation area $(\mathrm{RL}>\mathbf{1 2 . 5})$

- Yellow color : restricted access area $(0.25<\mathrm{RL} \quad 12.5)$

-White color : general public area (RL 0.25)

[RL : Radiation Level $(\mu \mathrm{Sv} / \mathrm{hr})$ ] 


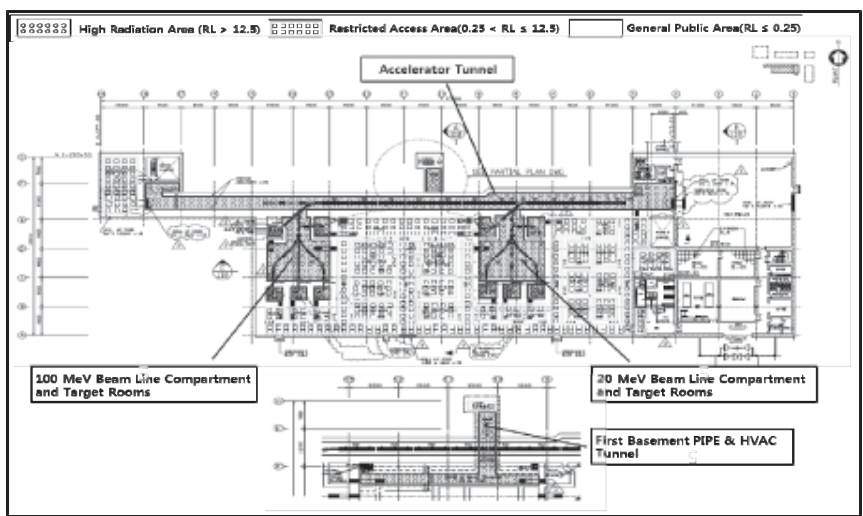

(a)

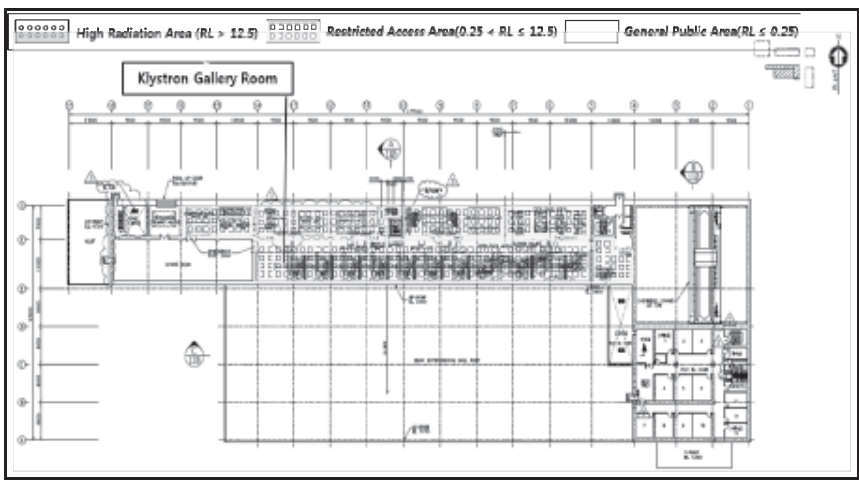

(b)

Fig. 2 Radiation area of accelerator \& beam experiment hall building in proton accelerator research center. (a) : First basement level and first floor, (b) : Second floor.

Table 1 Access Control Area Classification and access control devices.

\begin{tabular}{|c|c|l|}
\hline Access Control Area & $\begin{array}{c}\text { Radiation Level } \\
(\mathrm{RL}: \mu \mathrm{Sv} / \mathrm{hr})\end{array}$ & Access Control Devices \\
\hline \hline High Radiation Area & $\mathrm{RL}>12.5$ & $\begin{array}{l}\text { - Prior Operating Permit } \\
\text { - Alarm Pocket Dosimeter } \\
\text { - Mechanical Personal Key } \\
\text { - ID Card }\end{array}$ \\
\hline Restricted Access Area & $0.25<\mathrm{RL} \leq 12.5$ & $\begin{array}{l}\text { - Prior Operating Permit } \\
\text { - Alarm Pocket Dosimeter } \\
\text { - ID Card }\end{array}$ \\
\hline General Public Area & $\mathrm{RL} \leq 0.25$ & - ID Card \\
\hline
\end{tabular}

Table 1 shows the access control area classification and access control devices.

Access control of each area must follow Prior Operating Permit. In each access control area, personnel should carry devices such as, mechanical personal key (MPK), alarm pocket dosimeter, and ID Card to get in and out.

To protect each personnel against radiation exposure, authorized personnel can obtain APD to access the high radiation area and restricted access area. In prior access permit procedure, the MPK are provided to authorized personnel to help them work in high radiation area. It help us to figure out how many personnel are there in the high radiation area and to decide whether make the access doors open and close. Different ID cards setup for each area is required to get permissions according to the area classification.
The ID card for enter the high radiation area permits access to all three access control areas.

$\square$ The ID card for enter the restricted access area permits access only to restricted access area and general public area.

$\square$ The ID card for the general public area permits access only to general public area.

\section{Operation Mode}

PSIS is operated in four different access modes (free access, controlled access, no access, and search mode) in accordance with the degree of danger, as shown in Figure 3 Access modes : Free access, Controlled access, No access mode.

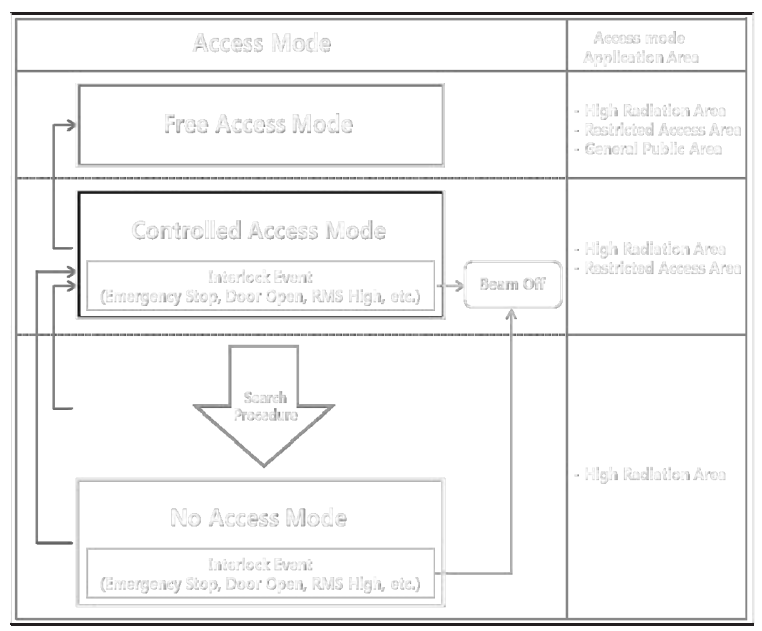

Fig. 3 Access level structure and access mode application area of PSIS.

Each mode's description, area characteristics, and condition show in Table 2, Table 3, Table 4, respectively.

Table 2 Free access mode.

\begin{tabular}{|c|l|}
\hline Access Mode & \multicolumn{1}{c|}{ Free Access Mode } \\
\hline \hline Description & $\begin{array}{l}\text { The mode that all access control doors are } \\
\text { opened. This mode can be applied as below; } \\
\text { - Initial installation and test run (which means } \\
\text { beam is not extracted) } \\
\text { • Under construction for accelerator extension }\end{array}$ \\
\hline \multirow{3}{*}{ Area Characteristics } & $\begin{array}{l}\text { - High Radiation Area } \\
\text { - Restricted Access Area } \\
\text { - General Public Area }\end{array}$ \\
\hline Condition & $\begin{array}{l}\text { - Accelerator off } \\
\text { - No radiation } \\
\text { - Non-interlocking of PSIS }\end{array}$ \\
\hline
\end{tabular}

Table 3 Controlled access mode.

\begin{tabular}{|c|l|}
\hline Classification & \multicolumn{1}{c|}{ Controlled Access Mode } \\
\hline \hline \multirow{3}{*}{ Description } & $\begin{array}{l}\text { The mode that opening/closing of access doors } \\
\text { are controlled by PSIS and only permitted } \\
\text { workers can access for each designated door. } \\
\text { This mode can be applied as below; } \\
\text { - Repair and inspection }\end{array}$ \\
\hline
\end{tabular}




\begin{tabular}{|l|l|}
\hline & - Conducting researches with beam \\
\hline Area Characteristics & $\begin{array}{l}\text { - High Radiation Area } \\
\text { - Restricted Access Area }\end{array}$ \\
\hline & $\begin{array}{l}\text { 1) When the accelerator is stopped, stay ready } \\
\text { and beam line off } \\
\text { - Applied area : Accelerator tunnel, each } \\
\text { beam line compartment and target room } \\
\text { - Interlocking PSIS }\end{array}$ \\
Condition \& \\
Applied Area \\
$\begin{array}{l}\text { 2) When the accelerator is operated, but beam } \\
\text { line Off }\end{array}$ \\
& $\begin{array}{l}\text { Each beam line compartment, each target } \\
\text { room not in use } \\
\text { - Interlocking PSIS }\end{array}$ \\
\hline
\end{tabular}

Table 4 No access mode.

\begin{tabular}{|c|l|l|}
\hline Access Mode & \multicolumn{2}{|c|}{ No Access Mode } \\
\hline \hline Classification & $\begin{array}{l}\text { (1) The mode that } \\
\text { access to the accel- } \\
\text { erator tunnel is proh- } \\
\text { ibited. }\end{array}$ & $\begin{array}{l}\text { (2) The mode that } \\
\text { access to the design- } \\
\text { nated beam line com- } \\
\text { partment and target } \\
\text { room are prohibited. }\end{array}$ \\
\hline Area Characteristic & - High Radiation Area \\
\hline Condition & $\begin{array}{l}\text { - Accelerator On } \\
\text { - Interlocking PSIS }\end{array}$ & $\begin{array}{l}\text { - Beam line On } \\
\text { - Interlocking PSIS }\end{array}$ \\
\hline
\end{tabular}

Search mode : Before the accelerator operation, search procedure is conducted by patrolling inside the high radiation area in order to ensure no personnel there. Search start/end button installed at high level radiation area access doors. Each search start/end button status is indicated on the PSIS display in the main control room.

\section{Access Control}

To control the access according to the radiation level within the area, access doors of PARC are classified into 3 categories according to the access door types. For each access door, associated access control devices are installed to gain entrance.

(1) Access from a general public area to another

$\square$ Condition for door opening : ID card

$\square$ Condition for door closing : auto close

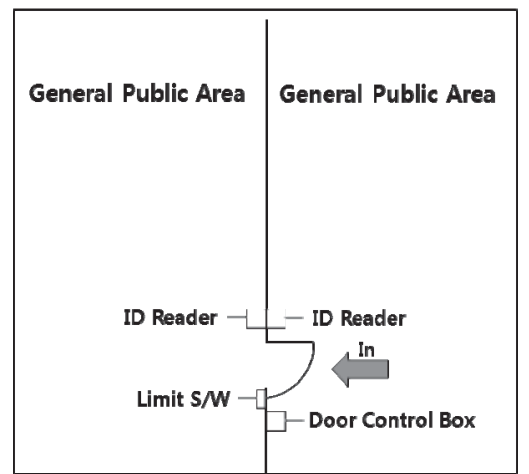

Fig. 4 Conceptual drawing of access door controlling -1 .

(2) Access from a general public area to a restricted area. In order to enter a restricted access area, personnel must pass through the access doors as described in Figure 5. Doors of each zone has several devices (APD bank, MPK bank, ID card reader etc.) to check up authority of the personnel. $\square$ Condition for door opening (Condition for door opening is two cases.) :

- High radiation area accessing personnel :

(1) ID card for high radiation area access

(2) RFID tag of APD withdrawn at APD bank

(3) RFID tag of MPK withdrawn at MPK bank

- Restricted access area accessing personnel :

(1) ID cards for restricted access area access

(2) RFID tag of APD withdrawn at APD bank

$\square$ Condition for door closing : auto close

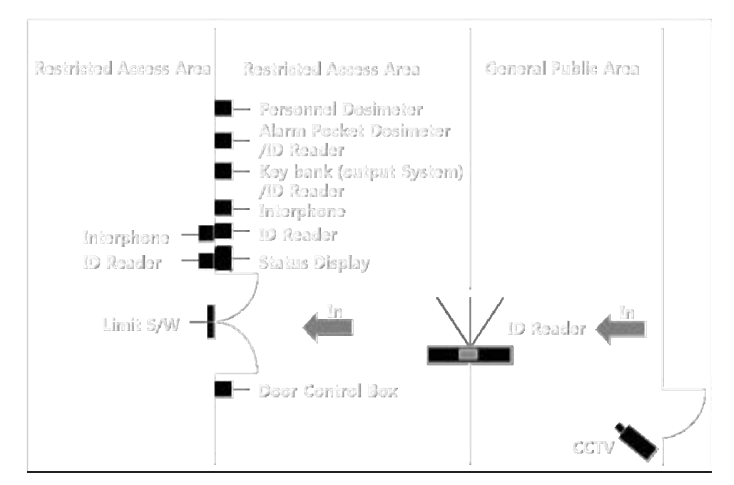

Fig. 5 Conceptual drawing of access door controlling -2 .

(3) Access from a restricted area to a high radiation area. In order to obtain access permission to a high radiation area, personnel must pass through shielding doors equipped with access control devices as described in Figure 6.

$\square$ Condition for door opening :

(1) Accelerator is turned off.

(2) Low levels of radioactivity.

(3) Number of inserted MPK should be same with the number of accessing personnel.

(4) Before accessing, personnel should report their access to a PSIS operator in main control room using Paging Phones.

(5) Then, a PSIS operator in main control room confirms the number of accessing personnel through CCTV.

6) By pressing an open button of PSIS Control Unit, the access door opens.

$\square$ Condition for door closing :

(1) By MPK withdrawal condition that Number of withdrawn MPK should be same with the number of personnel inside

(2) By pressing a close button installed on an access door, the access door closes

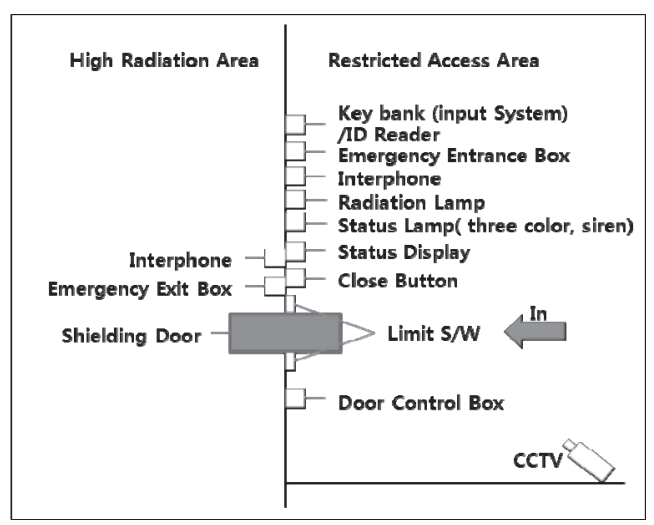

Fig. 6 Conceptual drawing of access door controlling -3 . 


\section{Accelerator Emergency Stop}

When an emergency stop signal by PSIS and RMS is generated, accelerator trip turns the accelerator's operation mode into non-operative one.

(1) PSIS-related accelerator emergency stop

(1) Emergency stop due to disorder of Programmable Logic Controller (PLC) equipment :

- Power supply is cut abnormally

- The PLC equipment fails

(2) Emergency stop due to disorder of the sequence of the access control system :

- Access control system operates abnormally.

(3) Emergency stop due to disorder of the access door open :

- The access door to a high radiation area is detected to be open

(4) Emergency stop in case of pressing emergency stop button

(5) Emergency stop in case of pressing emergency entrance/exit button

(6) etc.

Each status of Emergency stop button, Emergency entrance, and Exit button is show up in the PSIS display of the main control room.

(2) RMS-related accelerator emergency stop

(1) Emergency stop by signals from area monitor

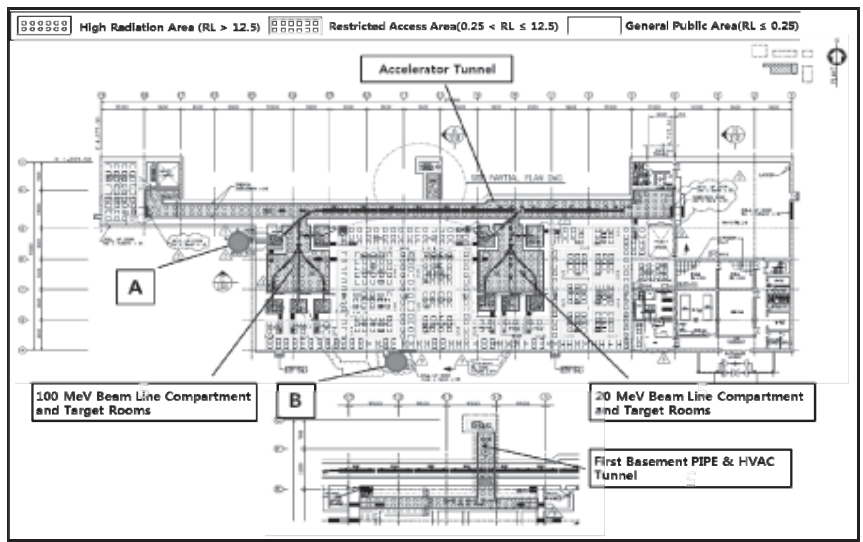

- Area monitor detection point : $A$ and $B$ area

- Detection type : proton recoil scintillator, Nal(TI) scintillator

Fig. 7 Radiation area of accelerator \& beam experiment hall building in PARC and area monitor detection point.

(2) Emergency stop by signals form Exhaust Monitor

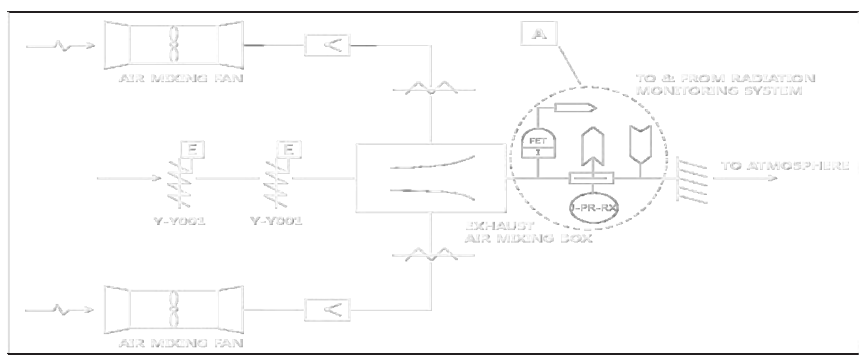

- Exhaust monitor detection point : A

- Detection type : 7-Be, 11-Be, 10-C, 11-C, 13-N, 14-O, 15-O, and 41-Ar

Fig. 8 Exhaust monitor detection point.
Table 5 shows the types and application conditions of accelerator emergency stop by operation mode. PSIS- related emergency stop and RMS- related emergency stop cases are applied only when the controlled access mode and the no access mode are operating.

Table 5 Types and application conditions of accelerator emergency stop by operation mode.

\begin{tabular}{|c|c|c|c|c|}
\hline \multicolumn{2}{|c|}{$\begin{array}{lll}\text { Emergency stop types } & \text { Access Mode }\end{array}$} & Free & Controlled & No \\
\hline \multirow{5}{*}{$\begin{array}{l}\text { PSIS- } \\
\text { Related } \\
\text { Emergency } \\
\text { Stop }\end{array}$} & $\begin{array}{l}\text { Emergency stop due to } \\
\text { disorder of Programmable } \\
\text { Logic Controller (PLC) } \\
\text { equipment }\end{array}$ & - & ○ & o \\
\hline & $\begin{array}{l}\text { Emergency stop due to } \\
\text { disorder of the sequence of } \\
\text { the access control system }\end{array}$ & - & o & ○ \\
\hline & $\begin{array}{l}\text { Emergency stop in case of } \\
\text { pressing emergency stop } \\
\text { button (Emergency stop } \\
\text { buttons are installed at the } \\
\text { high level radiation area.) }\end{array}$ & - & o & ० \\
\hline & $\begin{array}{l}\text { Emergency stop in case of } \\
\text { pressing emergency } \\
\text { entrance/exit button } \\
\text { (Emergency entrance/exit } \\
\text { button installed at high } \\
\text { level radiation area access } \\
\text { doors) }\end{array}$ & - & o & ० \\
\hline & Etc. & - & 0 & 0 \\
\hline \multirow{2}{*}{$\begin{array}{l}\text { RMS- } \\
\text { Related } \\
\text { Emergency } \\
\text { Stop } \\
\end{array}$} & $\begin{array}{l}\text { Emergency stop by signals } \\
\text { from Area Monitor }\end{array}$ & - & o & 0 \\
\hline & $\begin{array}{l}\text { Emergency stop by signals } \\
\text { form Exhaust Monitor }\end{array}$ & - & o & ० \\
\hline
\end{tabular}

\section{Hardware Configuration of PSIS}

(1) PLC System is designed to follow PSIS configuration and make its power supply and communication network available even in abnormal status through the redundancies by hot back-up.

(2) Isolation from other systems such as the RMS, the accelerator control system, and the utility control system, etc.

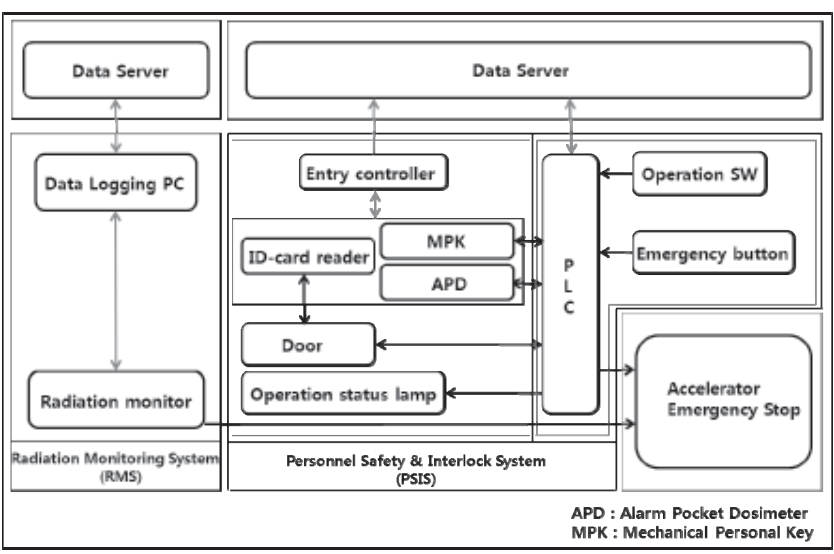

Fig. 9 Main flow diagram of the PSIS.

\section{CONCLUSION}

The proton beam experiment facilities, using high power $100 \mathrm{MeV}$ proton linear accelerator, include five of $20 \mathrm{MeV}$ experiment target rooms and five of $100 \mathrm{MeV}$ experiment 
target rooms on the basis of user requirements. When using high power $100 \mathrm{MeV}$ proton linear accelerator, a high radiation field is formed in the surrounding area. So the substances are radiation-activated. And according to beam current, target materials, beam irradiation, beam time and operation scenario, each target room has its own operation and access mode. $20 \mathrm{MeV}$ and $100 \mathrm{MeV}$ beam utilities are not allowed to operate simultaneously.

For this reason, special PSIS is required for protection from radiation hazards, abnormal accelerator operation, and unexpected accidents. This paper describes the core logics, the functions, and the characteristics to safely and efficiently operate PSIS in PARC.

\section{Acknowledgment}

This work was supported by Ministry of Education Science and Technology (MOST) of the Republic of Korea through the Proton Engineering Frontier Project.

\section{References}

1) 1) Y. S. Cho, H. J. Kwon, J. H. Jang, H. S. Kim, K. T. Seol, D. I. Kim, Y. G. Song, I. S. Hong, and Y.H. Kim, J. Korean Phys. Soc. 52, 721(2008).

2) 2) Y. H. Kim, J. H. Jang, and Y. S. Cho, Procceding of Particle Accelerator Conference 2007(Albuquerque, NM, 2007), P. 1553.

3) 3) Y. S. Cho, H. M. Choi, I. S. Hong, J. H. Jang, H. J. Kwon, H. S. Kim, K. Y. Kim, Y. H. Kim, K. T. Seol, and Y. G. Song, LINAC'06 (Knoxuille, 2006), P. 501. 